\title{
Establishment of a \\ Graduate Certificate Program in Biobased Industrial Products - Final Technical Report
}

\section{Kansas State University, Manhattan, KS John R. Schlup, Principal Investigator}

\author{
Project Title: $\quad$ Establishment of a Graduate Certificate Program in Biobased Industrial \\ Products \\ Covering Period: $\quad$ August 5, 2001 through August 4, 2005 (included a one-year, no-cost \\ extension, extending the project end date to August 4, 2005. \\ Date of Report: November 4, 2005 \\ Recipient: Kansas State University \\ Manhattan, KS \\ Award Number: $\quad$ DE-FG36-01ID14126 \\ Subcontractors: Pittsburg State University \\ Pittsburg, KS \\ Other Partners: None \\ Project Contact(s): \\ Technical: \\ John Schlup, 785-532-4319, jrsch@ksu.edu \\ Department of Chemical Engineering \\ Kansas State University \\ Manhattan, KS 66506-5102 \\ (785) 532-4319 \\ Business: Paul Lowe, 785-532-6804, plowe@ksu.edu \\ Initial Project Team: Marshall C. Garr, Contract Specialist, Procurement Services \\ Division \\ Valerie Sarisky-Reed, HQ Program manager \\ Matea McCray, DoE Project Manager \\ Joe Keller \\ DOE Project Team: \\ DOE-HQ contact - Valerie-Sarisky Reed, 202-586-1507, \\ (at end of project) \\ DOE Field Project Officer - Fred Gerdeman, 303 275-4935, \\ fred.gerdeman@go.doe.gov \\ DOE Contract Specialist - Margo Gorin, 303-275-4737, \\ margo.gorin@go.doe.gov \\ DOE Project Monitor - Bryna Berendzen, 303-275-4946 \\ bryna.berendzen@go.doe.gov
}




\section{Disclaimer:}

This report was prepared as an account of work sponsored by an agency of the United States Government. Neither the United States Government nor any agency thereof, nor any of their employees, makes any warranty, express or implied, or assumes any legal liability or responsibility for the accuracy, completeness, or usefulness of any information, apparatus, product, or process disclosed, or represents that its use would not infringe privately owned rights. Reference herein to any specific commercial product, process, or service by trade name, trademark, manufacturer, or otherwise does not necessarily constitute or imply its endorsement, recommendation, or favoring by the United States Government or any agency thereof. The views and opinions of authors expressed herein do not necessarily state or reflect those of the United States Government or any agency thereof.

Project Objective: Promote multidisciplinary education and training programs for graduate students in the area of biobased industrial products.

This Project Objective will be accomplished through:

1. graduate research programs related to biobased industrial products at Kansas State University and Pittsburg State University,

2. seminars to improve awareness among faculty and students regarding this research area,

3. involvement of an external advisory board to gain a broader perspective on these topics, and

4. establishment of a graduate certificate program in Biomass Technologies at Kansas State University.

The progress toward meeting each of these targets and the programs accomplishments in these areas are described in detail in the Program Outcomes section that follows information on Taxpayer Benefits.

Taxpayer Benefits

\section{From an Educational Perspective}

Three of the students supported continue to be active in the area of biobased industrial materials and processes, with two having taken positions in related industries. Two have continued career paths related to related biological sciences: one is in medical school and the other is completing a Ph.D. program in medicinal chemistry.

A graduate certificate program in biomass technologies has been approved by the College of Engineering at Kansas State University and continues to move through the approval process at the University.

A secondary major at the undergraduate level in Biological Engineering has been approved by the College of Engineering and continues to move through the approval process at the University.

Collaboration between related programs at Kansas State University and Pittsburg State University has been enhanced. In addition, the possibility of jointly offering related courses in this area is being explored by several universities in the region.

\section{From a Research Perspective}

Laboratory facilities have been established to explore thermocatalytic conversion of biobased resources. These resources have been very valuable in initiating collaborative activity between research groups in biobased materials and in catalysis. This collaboration is ongoing.

In addition, the thermocatalytic research above has demonstrated different product selectivities when fatty acids undergo pyrolysis and catalytic reactions over acidic and basic oxide catalysts. Preliminary data indicate that alkanes and alkenes can be formed by the catalytic deoxygenation 
of fatty acids. This could provide a source of raw materials from biomass that is very compatible to those currently obtained from petrochemicals.

Fatty acids and their associate triglycerides have been shown by a number of researchers to be valuable precursors for polymer synthesis. In this activity centered at Pittsburg State University, new synthetic routes to polymer precursors based upon plant-based oils and fatty acids have been identified, and their utility in polymer synthesis demonstrated. Implementation of this aspect of biomass utilization becomes much more likely as the tools available to researchers increase in number and in diversity.

Successful implementation of biomass technologies will require a means to identify feasible processes and to evaluate of their profitability and sustainability. Studies in the application of process graphs to bioprocessing have been initiated. Second law analysis is being implemented as an alternative for quantifying and evaluating the sustainability among a variety of process options. The construction of a computerized database for second law analysis is essential to successfully implement this approach; such a database is currently under construction.

\title{
Program Outcomes
}

\section{Graduate Research Programs Related to Biobased Industrial Products}

\author{
Students Supported \\ PSU, Department of Chemistry
}

(All M. S. Degree Candidates, Partial Support)

Shuangyi Wang ... Chemical Modification of Soybean Oil" (M.S. Thesis)

Charlene Lava ... "Structure and Properties of Functionalized Vegetable Oils and Oil-Based Polyurethanes" (M.S. Thesis)

Mile Lukic ... "Preparation and Properties of Fatty Acid-based Polyols" (M.S. Thesis)

Kwon Hong . . . "Phenolation of Soybean Oil" (M.S. Thesis)

\section{Department of Chemical Engineering, KSU}

Amol More (MS degree candidate, full support). "Deoxygenation of Fatty Acids to Hydrocarbon Feedstocks: Experimental Setup and Preliminary Studies" (M. S. Thesis, Kansas State University, July 2004).

Tengyan Zhang (PhD research associate in chemical engineering, partial support). Application of P-graph theory to design of bioprocessing plants.

Mr. Darren Strope (undergraduate research assistant, partial support) Catalytic decarboxylation of fatty acids.

Department of Apparel, Textiles, and Interior Design, KSU

Trina Das (MS degree candidate, partial support) ... "Bio-based Enzyme Processing of Natural Fiber (Kenaf, Flax, Wool, Alpaca, Mohair, Llama, Camel and Cashmere)"

Rohit Uppal (doctoral candidate, partial support) ... "Morphology of High Performance Fibers Including Biopolymers for Medical Purposes"

\section{Current Professional Status of Students Supported}

Several of the students supported by this program remain active in biological sciences, biological engineering, and related fields. Charlene Lava is attending medical school at the University of Kansas, and Kwon Ho Hong is working on a Ph. D. in medicinal chemistry at the University of Kansas. Shuangyi Want is employed by GlycoMimetics (Rockville, MD). Amol More is employed 
as a bioprocessing engineer with Missouri Bio-Fuels, LLC (Bethel, MO). Tengyan Zhang continues as a research associate focusing on developing new design tools for bioprocessing.

Based upon the students above, the program was very successful in preparing professionals in careers related to biomass technologies. Without this funding mechanism, several of these students would not have had an exposure to these technologies and would not have had the opportunities to develop the skills need to pursue their current career paths. 


\section{Patents:}

None

\section{Overview of Results from Research Projects Supported:}

\section{Polymers from Biomass ... Polymers from Soybean Components}

The Kansas Polymer Research Center (KPRC) was the lead institution for this research effort under the leadership of Dr. Zoran Petrovic. For several years, the KPRC at Pittsburg State University has been successful in synthesizing a variety of novel monomers from soybean and other vegetable oils. These functionalized oils have been included in the formulation and processing of polyurethanes, unsaturated polyesters, and epoxies. All of the students supported at Pittsburg State University were involved in research projects focusing on chemical modification of soybean oils and their fatty acids, the utilization of these modified biobased materials in the synthesis of polymers, and the characterization of both the modified oils and the resulting polymers.

Polyurethanes were of most interest in this effort. The formation of polyurethanes from soybean oil and its fatty acids can occur via synthesis of polyols and of epoxidized species. Epoxidation, hydroxylation, and crosslinking at the double bonds in the vegetable oils were investigated as routes to synthesis of polyurethanes from vegetable oils (thesis by C. C. Lava). The kinetics of the epoxidation reactions was studied to optimize the conversion and selectivity to these intermediates. Hydroxylation of epoxidized soybean oils was studied as a route to polyol formation. The parameters for the reaction were studied in order to increase $\mathrm{OH}$ content and to minimize the by-products formed. The impact of the type of vegetable oil (soybean, corn, canola, sunflower, mid-oleic sunflower, and linseed) was studied. Polyols having similar compositions and functionality yielded polyurethanes which had similar properties $\left(T_{g}\right.$, swelling, thermal, and mechanical).

Fatty acid polyols were synthesized via transesterification involving methyl esters of hydroxyl fatty acids and ethylene glycol, diethanolamine, and triethanolamine (thesis by M. Lukic). The result was polyols having lower viscosities and higher reactivities. The polyurethanes prepared from these new starting materials had properties comparable with polyurethanes synthesized from triglyceride polyols.

Soybean oil intermediates were formed following reaction with chlorohydrin, formic acid, heteropolyacid, molecular oxygen, and phenol (thesis by S. Wan). The Prins reaction and enzymatic catalysis were investigated as well. Most of these procedures did not yield high $\mathrm{OH}$ numbers. The exception was a formic acid one-pot-multistep procedure, best conducted at room temperature. The best procedure for obtaining epoxidized soybean oil was involved enzymatic Epoxidation with an $85 \%$ conversion being possible. The addition of an aromatic ring onto the soybean oil chain was demonstrated as well.

K. H. Hong continued the studies on synthesis of phenolated soybean oil. Phenolated derivatives of soybean oil, metathesized soybean oil, and epoxidized soybean oil were obtained via Friedel-Crafts reactions. Complete conversion was reported for reaction times as little as 10 minutes. These phenolated oils were then reacted with hexamethylenetetramine to yield phenolic resins. The synthesis of an aliphatic-aromatic polyurethane was demonstrated as well.

\section{Deoxygenated Hydrocarbons from Vegetable Oils}

Drs. Schlup and Hohn (Department of Chemical Engineering, KSU) coordinated this research project. The research program was initiated to obtain long chain alkanes and alkenes through deoxygenation of fatty acids derived from biomass. The crops currently most applicable for use as fuel and petrochemical feedstocks are those which contain long chain hydrocarbons; i.e., plants containing molecules chemically similar to crude oil. These plant products could be substituted directly in the production of fuels and chemicals. Some investment in processing technology will be required to obtain hydrocarbon feedstocks from fatty acids; the utilization of the hydrocarbons produced, however, can rely on existing petrochemical technology. 
The program objectives were two-fold: (1) to develop the capability to study thermocatalytic reactions related to bioprocess and (2) to demonstrate that capability with preliminary studies on the thermocatalytic conversion of fatty acids to alkanes and alkenes.

A Robinson-Mahoney stationary basket catalytic reactor was set-up to investigate catalytic deoxygenation of fatty acids to hydrocarbons. The experimental procedure and sampling techniques were successfully developed for low pressure operation. Oleic acid was selected as a model compound. Pyrolysis and catalysis over ZSM-5 and ZnO catalysts were studied. The reactor was operated at atmospheric pressure. While reaction temperatures between $200^{\circ} \mathrm{C}$ and $450^{\circ}$ were investigated, the initial focus was on lower temperatures $\left(200^{\circ} \mathrm{C}\right.$ and $\left.250^{\circ} \mathrm{C}\right)$ to facilitate data acquisition as familiarity was gained with the system. Overall conversion of the carboxylic acid functional group was monitored via disappearance of $-\mathrm{COOH}$ in the oleic acid. Gas chromatography was employed to monitor the products present in the both the gas and liquid phase products.

Light hydrocarbons gases, $\mathrm{CO}$, and $\mathrm{CO}_{2}$, were the major products observed at the lower temperatures. Pyrolysis of oleic acid resulted in very low conversion. Products characteristic of cracking reactions were observed with ZSM-5 catalyst. The $\mathrm{ZnO}$ catalyst resulted in formation of a metallic soap via the fusion reaction; $\mathrm{CO}$ and $\mathrm{CO}_{2}$ were formed in an oxygen free atmosphere indicating that deoxygenation had occurred as well. The presence of $\mathrm{CO}$ and $\mathrm{CO}_{2}$ in the gas phase and the disappearance of the carboxylic acid group in the liquid phase indicated that catalytic decarboxylation occurred over both catalysts.

\section{Intelligent Design of Bioprocessing}

To identify process flowsheets which are feasible as well as superior in terms of their costs and sustainability is extremely difficult. Process graph ( $P$-graph) theory has been shown to be a remarkably efficient and robust method that permits examination of numerous, diverse process schemes. Since August 2004, a postdoctoral student has been involved applying these concepts to intelligent design of bioprocesses. The particular emphasis of this preliminary research effort is to evaluate the thermodynamic efficiency of each such process system and to select superior ones by comparing their costs and their available energy (exergy) conservation efficiencies. The final ranking of the flowsheets can be accomplished by considering both the cost and the available energy efficiency, according to well-established methods for multiobjective optimization. The effort to date has focused on developing a computerized database so that the exergy analysis can be integrated with P-graph process design algorithms. This will provide a rigorous approach to the calculation of the sustainability of process alternatives.

\section{Publications/Presentations:}

\section{Oral Presentations}

"Fatty Acid - Based Polyols and Polyurethanes," Zoran S. Petrovic, and Mile Lukic, Wei Zhang and William Shirley, , The $7^{\text {th }}$ Yugoslav materials Research Conference YUCOMAT 2005, Herceg Novi 12-16, 2005.

"Effect of $\mathrm{NCO} / \mathrm{OH}$ Molar Ratio on Properties of Soy-Based Polyurethane Networks," Zoran S. Petrovic, Wei Zhang, Alisa Zlatanic and Charlene C. Lava. Presented at the ACS-PMSE Orlando, April 2002.

"Establishment of a Graduate Certificate Program in Bio-based Materials Science and Engineering," J. R. Schlup. Presented at the session on Developing Industrial Bio-Based Technology Curricula at the $223^{\text {rd }}$ American Chemical Society National Meeting, Orlando, FL, April 7 - 11, 2002.

"Structure-property relationships in different types of vegetable oils," Andrew Guo, Sharlene Lava, Alisa Zlatanic and Zoran Petrovic. Presented at the ACS Meeting, Boston, August 2002.

"Establishment of a Graduate Certificate Program in Biobased Materials Science and Engineering" John Schlup, Kansas State University. Presented as a part of session on Education Initiatives for 
Biomass Utilization at the conference "Creating value for Biobased Resources," Kansas City, MO, November $11-13,2003$.

"Structure-Property Relationship in Vegetable Oil-Based Polyurethanes," Zoran Petrovic, Kansas Polymer Research Center, Pittsburg State University. Presented as a part of session on Biobased Materials from Oils at the conference "Creating value for Biobased Resources," Kansas City, MO, November $11-13,2003$.

"Polyurethanes Based on Hydroformylated Soybean Oil," Andrew Guo, Kansas Polymer Research Center, Pittsburg State University. Presented as a part of session on Biobased Materials from Oils at the conference "Creating value for Biobased Resources," Kansas City, MO, November 11 - 13, 2003.

"Preliminary Studies on the Deoxygenation of Fatty Acids to Hydrocarbon Feedstocks," A. A. More, K. Hohn, and J. R. Schlup. Oral Presentation at the $39^{\text {th }}$ Midwest Regional Meeting of the American Chemical Society, Manhattan, KS, October 20-22, 2004.

"Assessment of Sustainability-Potential Hierarchical Approach," Fan, L. T., T. Zhang, J. Liu, J. R. Schlup, F. Friedler, and B. Bertok. Presented at the session on Thermodynamics for Sustainability (co-sponsored by DECHEMA), AIChE Annual Meeting, Cincinnati, OH, October 30 - November 4, 2005.

\section{Student Presentations ... Published Abstracts}

V. Jayachandran and G.N. Ramaswamy, "Nanoparticles Synergists for Brominated Flame Retardants: For Textile and Composites Industries", Agricultural Products Utilization Forum Conference on Biobased Products, Kansas City, KS, Nov. 10 - 12, 2002, pp. 57

H. Uppala and G.N. Ramaswamy, "Chemical Compatibility of Textile Softeners and Phosphorus Flame Retardants: For Textile Industry", Agricultural Products Utilization Forum Conference on Biobased Products, Kansas City, MO, Nov. 10 - 12, 2002.

R. Virk and G.N. Ramaswamy, "Plasma Treatment and Antimicrobial Finishes for Medical Textiles", Agricultural Products Utilization Forum Conference on Biobased Products, Kansas City, MO, Nov. 10 12, 2002.

\section{Poster Presentations}

"Bio-based Process Development: Enzyme Treatment of Merino Wool, Rambouillet Wool, Llama, Alpaca, Camel, and Mohair," Trina Das and Gita N. Ramaswamy, Department of Apparel, Textiles, and Interior Design, Kansas State University. Presented as a part of the Poster Session at the conference "Creating value for Biobased Resources," Kansas City, MO, November 11 - 13, 2003.

"Preparation of Soy-Based Polyols using a Methoxy Catalyst," R. Oshel, M. Ionescu, I. Javni, J. Stojadinov, and Z. Petrovich, Kansas Polymer Research Center, Pittsburg State University. Presented as a part of the Poster Session at the conference "Creating value for Biobased Resources," Kansas City, MO, November $11-13,2003$.

"Epoxidation of Soybean Oil," S. Wang and Z. Petrovic, Kansas Polymer Research Center, Pittsburg State University. Presented as a part of the Poster Session at the conference "Creating value for Biobased Resources," Kansas City, MO, November 11 - 13, 2003.

"Catalytic Deoxygenation of Fatty Acids to Hydrocarbon Feedstocks," A. A. More, J. R. Schlup, and K. L. Hohn. Presented as a part of the program at the Bioprocessing \& Industrial Value-Added Program (BIVAP) Building Dedication, Manhattan, KS, October 15, 2004.

"Preparation and Properties of Fatty Acid-Based Polyols and Polyurethanes" by Wei Zhang, Zoran Petrovic, Mile Lukic and William Shirley. Poster Presentation at the $39^{\text {th }}$ Midwest Regional Meeting of the American Chemical Society, Manhattan, KS, October 20-22, 2004. 


\section{Refereed Publications}

Alisa Zlatanic, Charlene Lava, Wei Zhang and Zoran S. Petrovic, "Effect of Structure on Properties of Polyols and Polyurethanes Based on Different Vegetable Oils," J.Polym.Sci. Polym.Phys. (submitted).

Alisa Zlatanić, Charlene Lava, Wei Zhang and Zoran S. Petrović, "Effect of Structure on Properties of Polyols and Polyurethanes based on Different Vegetable Oils," Accepted for publication in J. Polym. Sci. Polym. Phys.

A. More, J. R. Schlup, and K. Hohn, "Catalytic Deoxygenation of Fatty Acids: Conversion of Oleic Acid in the Presence of ZnO and ZSM-5" by More, Schlup, and Hohn. Submitted for publication in Biomass and Bioenergy.

L. T. Fan, Tengyan Zhang, and J. R. Schlup, "Energy Consumption vs. Energy Requirement." Accepted for publication in Chemical Engineering Education.

Z. S. Petrovic, Kwon Ho Hong, W. Shirley, and M. lonescu, "Phenol Alkylated Soybean Oil," Polymer Preprints, 2005, 46(1), p .294.

Zoran S. Petrovic, and Mile Lukic, Wei Zhang and William Shirley, Academy of Science and Arts of Serbian Republic, Scientific Sessions Vol VII , Section of natural, Mathematical and Technical Sciences vol.4, Theoretical and Experimental Investigation of Nanomaterials, Banja Luka 2005, p.261-271.

Zoran S. Petrovic , Kwon Ho Hong , William Shirley and Mihail lonescu, "Phenol Alkylated Soybean Oil," Polymer Preprints, 2005, 46(1), 294-295.

Zoran S. Petrovic', Wei Zhang, Alisa Zlatanic, Charlene C. Lava and Michal Ilavský, "Effect of $\mathrm{OH} / \mathrm{NCO}$ Molar Ratio On Properties Of Soy-Based Polyurethane Networks," J. Polymers and Environment, 10(1/2), April 2002, p.5-12.

Z. S. Petrovic, Alisa Zlatanic, Charlene C. Lava, Snezana Sinadinovic-Fiser, "Epoxidation of Soybean Oil in Toluene with Peroxoacetic and Peroxoformic Acids - Kinetics and Side Reactions, Eur. J. Lipid Sci. Technol. 104 (2002), No. 5, 293-299.

Z. S. Petrovic, Alisa Zlatanic, Charlene C. Lava, Snezana Sinadinovic-Fiser, "Epoxidation of soybean oil in toluene with peroxoacetic and peroxoformic acids - kinetics and side reactions," Eur. J. Lipid Sci. Technol. 104 (5) (2002), pp. 293-299.

\section{Seminars and Conferences Supported}

\section{Seminars Supported}

1. Dr. J. S. McLaren (Inverizon ${ }^{\circledR}$ International, Inc.), "The Potential Role of Biotechnology and Genomics as a Platform for Renewable Resources, and a More Sustainable Future", April 3, 2002. (As a consequence of Dr. McLaren's visit, collaboration between his organization and several individuals at KSU has been initiated regarding utilization of grain sorghum.)

2. Dr. Richard Wool (Department of Chemical Engineering, University of Delaware), "Materials from Soybeans" Monday, July 8, 2002

3. Dr. Mark Paster (U. S. Department of Energy), "Biobased Products and Bioenergy: A Federal Perspective," August 16, 2002.

4. John Sheehan (National Renewable Energy Laboratory) spoke on total life-cycle analysis of bioethanol from biomass. (April 2005).

5. Dr. David G. Rethwisch (Department of Chemical and Biochemical Engineering, University of lowa), "Biocatalytic Epoxidation of Natural Oils," (April 2005) 


\section{Regional Conference Supported}

The Agricultural Products Utilization Forum (APUF) at Kansas State University organized a conference entitled, "Creating Value for Biobased Resources," which was held in Kansas City, Mo., November 11-13, 2002. The Biobased Materials Science and Engineering graduate certificate program played an integral role in planning and sponsoring this conference. The conference was national in scope as participants came from as far as California, Michigan, and Georgia.

An overview of the conference can be obtained by visiting the conference website at http://www.oznet.ksu.edu/pr apuf/Conference\%202002.htm. In addition, the program along with abstracts of the presentations can be found at the website http://www.oznet.ksu.edu/pr apuf/Book\%20of\%20\%20Abstracts.htm.

One of the sessions at the conference concerned recent educational initiatives related to biomass utilization. The presentations from that session are listed in the table on the following page. Each of these speakers is a participant with an educational initiative sponsored by the Department of Energy.

\section{Technical Session 2 (Concurrent) - Education Initiatives Biomass Utilization \\ Robert Brown, lowa State University, Chair}

"Multi Disciplinary Graduate Training in Technologies for a Biobased Economy" Mark Worden, Michigan State University

"Graduate Education for the Future Bioprocess Engineer" Mark Eiteman, University of Georgia "Developing a Biobased Products Graduate Program" Jerry Lalman, Oklahoma State University

"Assessing the Economic Viability of Biobased Products for Missouri "Value-Added Crop Production" Nicholas Kalaitzandonakes, U. of Missouri

Break

"Renewable Resources \& Technology Graduate Program at lowa State University" Robert Brown, lowa State University

"Establishment of a Graduate Certificate Program in Biobased Materials Science and Engineering" John Schlup, Kansas State University

"Opportunities for Biobased Graduate Education at Nebraska" Curtis L. Weller, University of Nebraska

\section{Establishment of a Graduate Certificate Program in Biomass Technologies at Kansas State University}

A certificate of graduate studies in Biomass Technologies is being established at Kansas State University (KSU) along with the development of a related program of study at Pittsburg State University, Pittsburg, KS. At KSU, the program of study will be coordinated through the internal advisory board of the Bioprocessing and Industrial Value-Added Program (BIVAP); the certificate of graduate studies will be awarded through the Graduate School of Kansas State University. This certificate being established is an interdisciplinary program of study that will:

1. ensure participating students receive a broad education in several disciplines related to Biobased Industrial Products,

2. provide a documented course of study for students preferring a freestanding certificate program, and

3. provide a paradigm shift in student awareness away from petroleum-based feedstocks to the utilization of renewable resources for fuels and chemical feedstocks. 
The graduate certificate in Biomass Technologies currently undergoing approval at KSU will accomplish these goals by:

1. providing exposure to several academic disciplines key to Biobased Industrial Products;

2. improving university/industry collaboration through both an internal and external advisory board assisting BIVAP at KSU and distance learning opportunities;

3. expanding the disciplines represented on the students' supervisory committee;

4. promoting seminars related to Biobased Industrial Products and biomass technologies that draw upon expert speakers representing several disciplines; and

5. increasing collaboration between disciplines.

During the first year of the project, the academic requirements for the proposed graduate certificate in biobased industrial products were defined. The proposed graduate certificate was approved by the College of Engineering (the college through which the certificate was to be submitted to the Graduate School). Support letters are currently being obtained from participating departments and colleges. At that time Pittsburg State University did not provide graduate certificates within their graduate school; they decided not to pursue this option at that time. Therefore, PSU students pursued specifically designed courses of study within their degree program consistent with an interdisciplinary emphasis in biobased industrial products and the certificate program proposed at KSU.

Implementation of the graduate certificate program was delayed for several reasons. The role of key faculty began to change before final approval was sought. The University's commitment to the Bioprocessing and Industrial Value-Added Program (BIVAP) impacted the function of the Ag Product Utilization Forum (APUF), which had been designated originally to have oversight of the proposed graduate certificate program. These two factors obviously would significantly impact the proposed graduate certificate program.

The Biobased Industrial Value-Added Program (BIVAP) building was dedicated fall of 2004 at Kansas State University. Recently APUF has ceased to function as a separate entity; its role is being assumed by the Internal Advisory Board for BIVAP. The Internal Advisory Board currently consists of eighteen (18) faculty representing two colleges, six departments, and five administrative units. Members of the External Advisory Board will be asked to provide guidance for the graduate certificate program. Currently this group is composed of five (5) advisors representing a diverse group of industries. Both of these advisory groups have met at least annually since 2004; in addition, subgroups meet throughout the year to address particular issues relevant to BIVAP and related programs.

Having modified the previous administrative structure for the graduate certificate program to reflect the changes above, a revised version of the proposed graduate certificate has been approved by the Course and Curriculum Committee of the College of Engineering. The revised version also included recent changes in both the faculty and courses involved. Approval by the college faculty is expected in November 2005. Once approved, the proposed graduate certificate will be distributed among the participating departments and colleges to ensure that there are no conflicts with courses and other resources and subsequently will be submitted to the Graduate School for their approval.

\section{Other Educational Initiatives Pursued Related to Biomass Technologies}

\section{Proposal of a Secondary Major in Bioengineering}

A proposal to establish an interdisciplinary undergraduate secondary major in bioengineering that would include biobased materials science and engineering and biomass technologies has been approved by the Course and Curriculum Committee of the College of Engineering. It will be presented to the full faculty of the College of Engineering for approval in November 2005. 


\section{Multiuniversity Consortium to Deliver Graduate Courses in Bioprocessing}

Discussions have been initiated with several universities in the Midwest to build a consortium that will deliver graduate courses related to bioprocessing and biobased materials to our students. A teleconference in January 2005 began to define the collaboration and to decide how best to proceed. Mutual course offerings were planned for the fall 2005 semester. A second teleconference was held during spring 2005. While a formal consortium is not in place at this time, collaboration to provide information on courses of mutual interest began with the fall 2005 semester.

\section{Program Needs Assessment}

A market study on the demand for bioprocessing courses, particularly via some form of distance education was initiated spring 2005. This study is being performed by the Institute for Academic Alliances, Kansas State University, in collaboration with Drs. Madl and Schlup. Its focus is on industry and student demand for a graduate degree or certificate program via distance education in the area of biomass technologies. This activity is on-going at this time.

\section{Concluding Discussion/Overall Analysis}

These funds have been invaluable in encouraging the development of educational initiatives in biomass technologies, particularly the graduate certificate program. It is one thing to obtain research funds; it is often much more difficult to obtain support to develop new educational initiatives. Funding for such educational initiatives is very beneficial to their development. Such resources provide educators with a means of exploring new ideas and opportunities and provide a mechanism for rewarding researchers and educators to think beyond existing models. Student support provides a means for attracting students to new research disciplines and educational alternatives.

In addition, the funds provided by the Department of Energy have been very useful in developing further interaction between related research groups at Kansas State University and Pittsburg State University. They have also led to preliminary interactions with institutions outside the state regarding alternative means of delivering coursework topics related to biomass technologies.

For these initiatives to be most effective, it is important to provide them with stability. Graduate students need to be recruited into these programs, but this typically cannot start until the funds are awarded. Completion of their educational programs and research projects require time; stability in funding permits the students and faculty to plan their educational programs. Unfortunately the interruption of funding following the second year of this project suddenly limited the number of students that could be involved in the project. When funding of the third year was later approved, care had to be taken in designing student participation since only one year of funding was to be available. 